\title{
بقلم: مساعد رئيس التحرير
}

يصدر العدد الثالث من المجلد الثامن للمجلة المصرية لعلم النفس الإكلينيكي والإرشـادي، وهو يحمـل خبرا

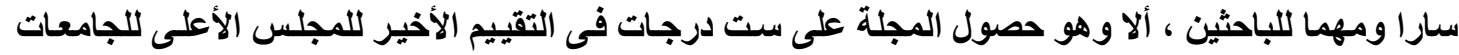

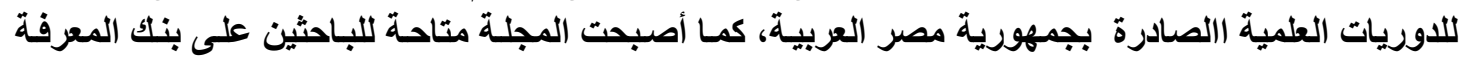

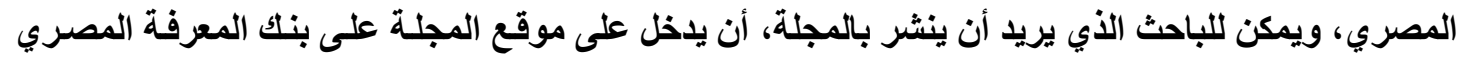

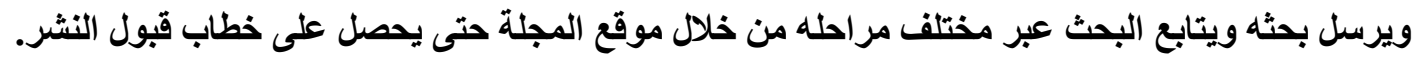

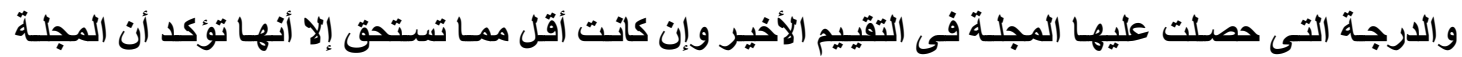

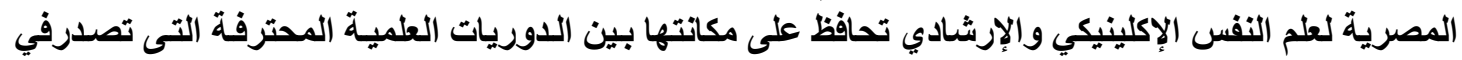

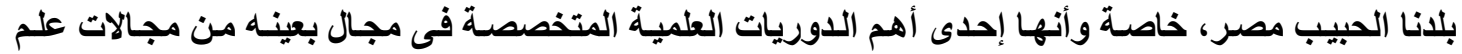

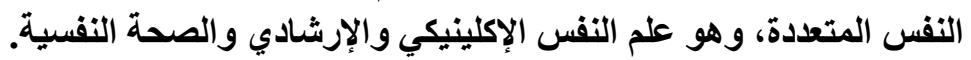

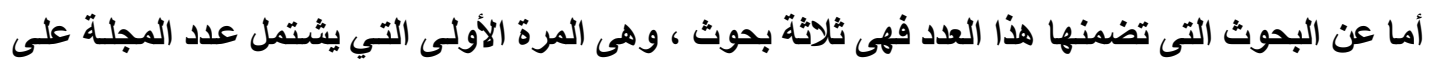

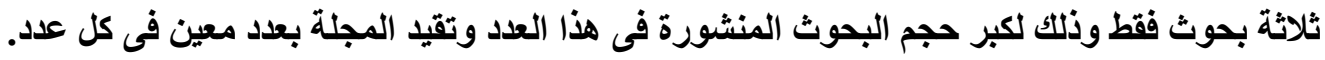

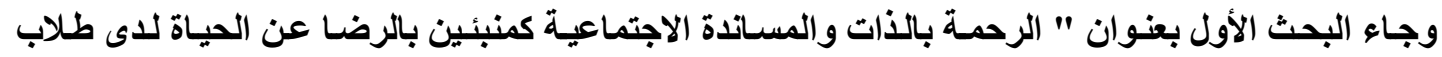

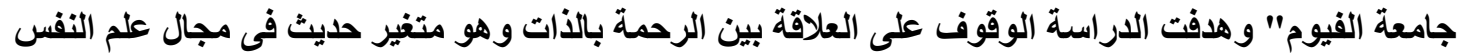

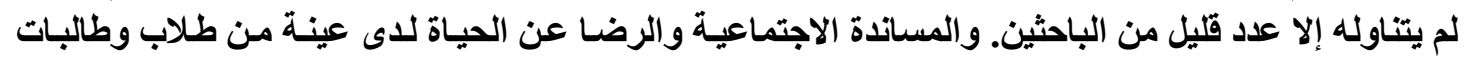

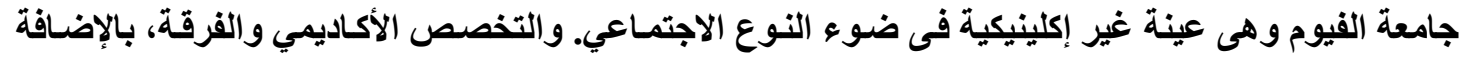

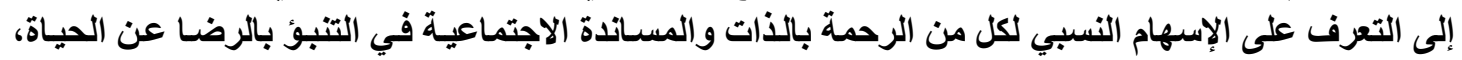

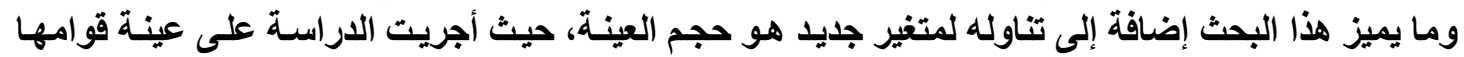

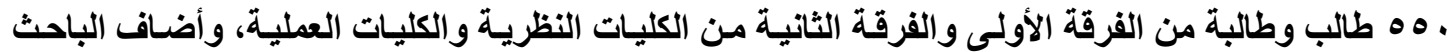

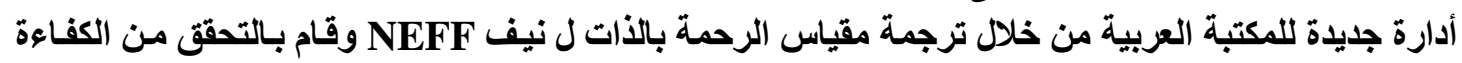

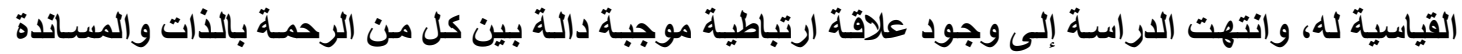

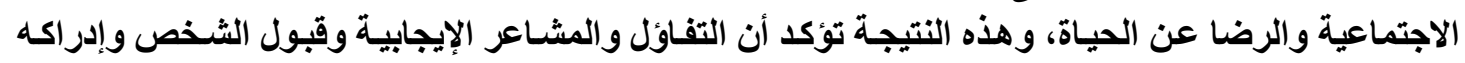

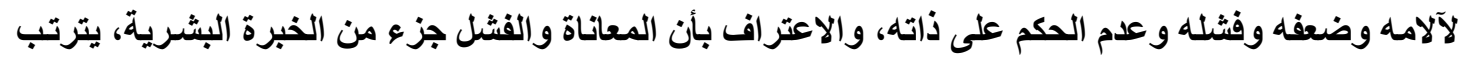

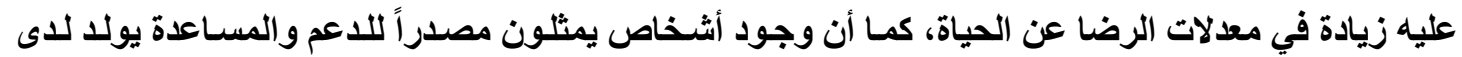

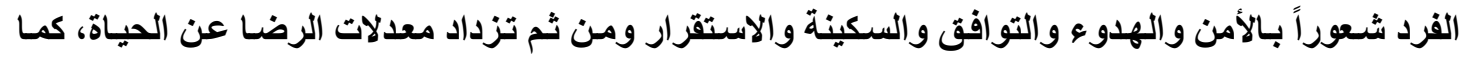

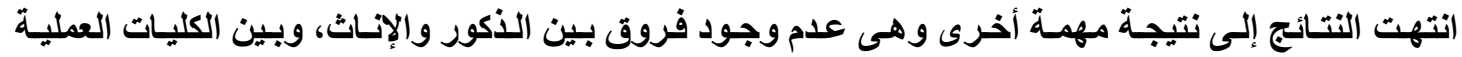

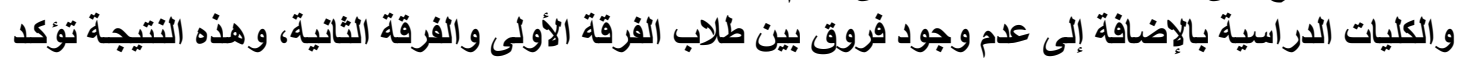

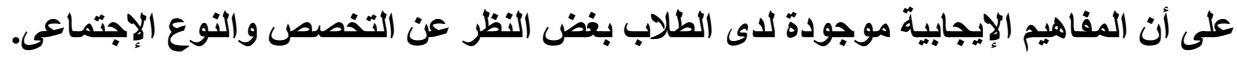

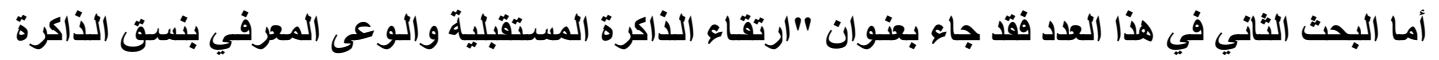

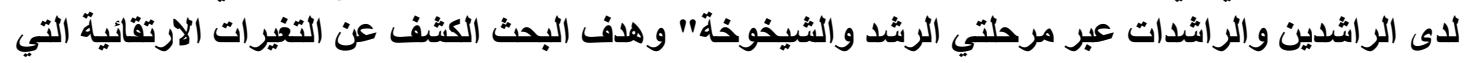

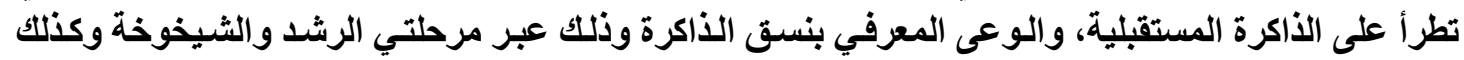

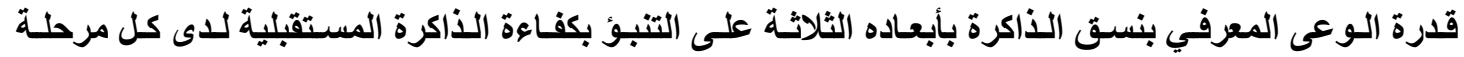

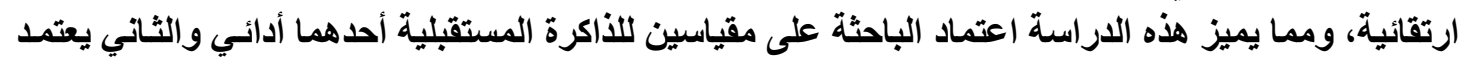

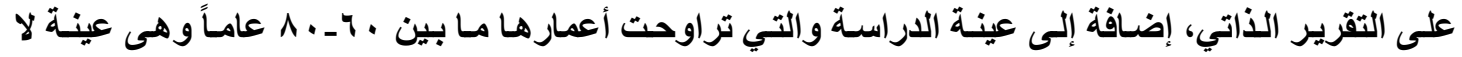

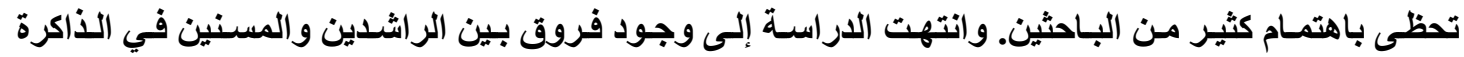

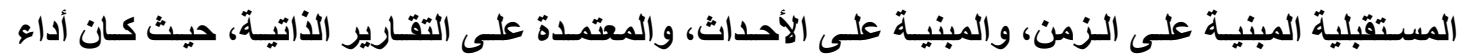


الراشدون الأصغر سناً أفضل من المسنين الأكبر سناً، وهذا يؤكد على ارتبـاط التدهور في بعض القدرات

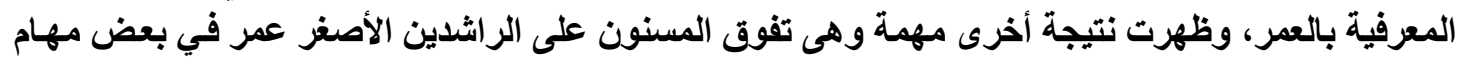

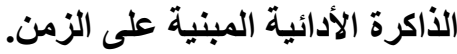

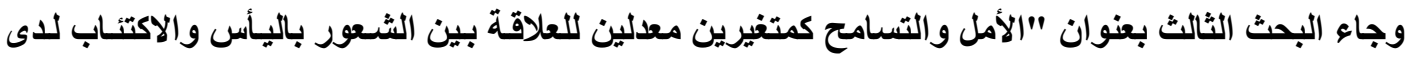

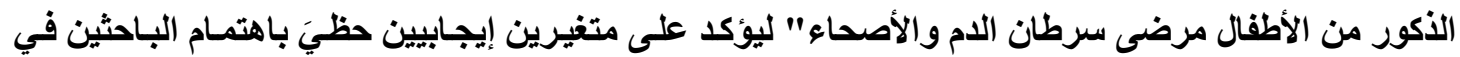

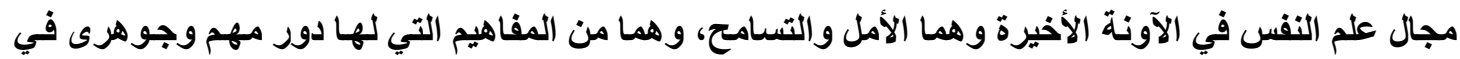

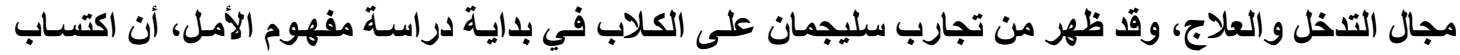

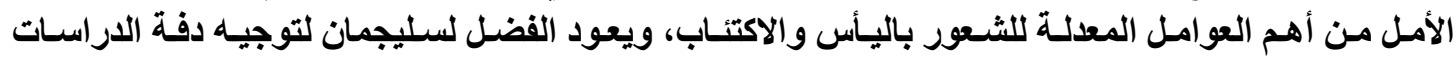

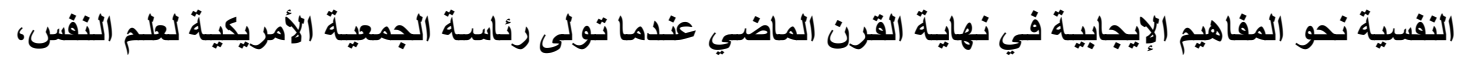
حيث رأى أن الدور التقليدي لعلم النفس قد انحصر في التركيز على دراسلة الجوانب التبل السلبية في الثخصية

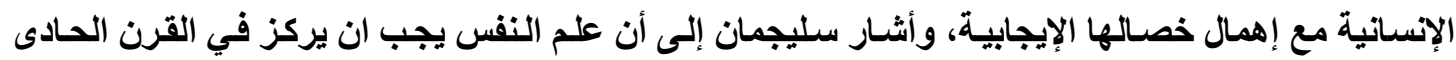

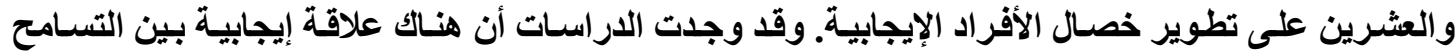

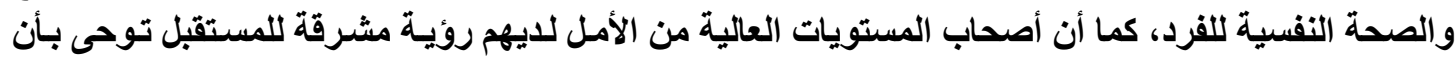

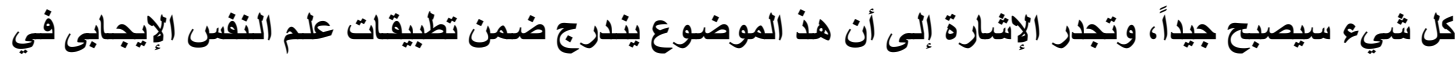

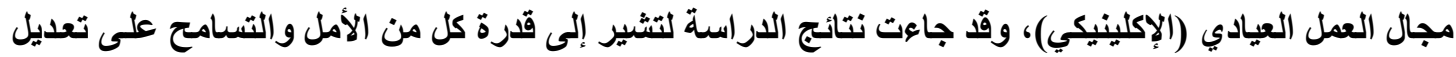

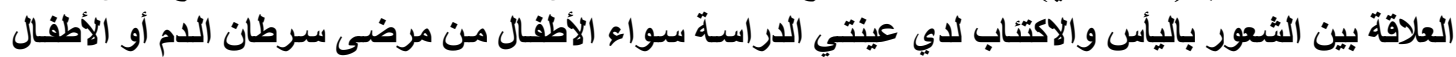
الأصحاء.

وفى النهاية أدعو الله سبحانه وتعالى أن يجعله علما نافعاً للباحثين وللمثقفين ولعامة النـاس، والله من وراء القصد إنه نعم المولى ونعم النصير.

د. عماد عبد المقصود محجوب

مدرس علم النفس الإكلينيكي (الفئات الخاصة)

بكلية الآداب - جامعة القاهرة 